\title{
Square Design: from digital analysis to urban design
}

\author{
Camilla Pezzica \\ University of Pisa, Italy \\ camilla.pezzica@gmail.com \\ João V. Lopes \\ ISCTE-Instituto Universitário de Lisboa, \\ Vitruvius FABLAB, ISTAR-IUL,Portugal \\ jvsls@iscte.pt
}

\author{
Alexandra Paio \\ ISCTE-Instituto Universitário de Lisboa, \\ Vitruvius FABLAB, ISTAR-IUL,Portugal \\ alexandra.paio@iscte.pt
}

\begin{abstract}
This work proposes and tests, through the application to a Portuguese case study (Largo da Graça in Lisbon historic center), an original method of analysis specifically oriented to the study of public squares. Collecting contributions from the disciplines of urban morphology, social studies, environmental and site analysis, the presented methodology aims to synchronously and multi-dimensionally characterize and classify urban spaces at a multi-scale scale level, by coordinating multiple tools and advanced analysis techniques, in a process whose ultimate goal is to understand and improve the quality of public open spaces and to encourage its appropriation and enjoyment by the local community and the visitors.
\end{abstract}

Keywords: Design research; Public space design; Parametric modelling; Multidimensional analysis; Space syntax

\section{Introduction}

Largo da Graça, initially known with the name of Largo da Graça Convent, is located at the top of the slope where the homonym Convent lies, in the core of Graça neighborhood inside the historic center of Lisbon. The surrounding area is mainly residential (urban zone $A$, consolidated) with a total population of 20531 inhabitants, and an average dimension of families of 2,01 people. Apart from the residents, Largo da Graça is frequented by a big number of tourists that arrive with the traditional tram 28 to visit the Miradouro da Graça, located in front of the convent. Largo da Graça has a diversified character; it consists of an irregular sequence of sub-areas. One of them is monumental and strongly linked to the convent and another one, larger, is commercial and made of buildings of a lesser architectural interest. The existence of 6 toponymical inscriptions along an area of intervention of $15620 \mathrm{~m} 2$ witnesses the complex character of this space. In urban toponymy the word Largo and the Latin largus is used to identify a public space morphologically distinct in the urban morphology, in which the transit function is as important as its functioning as a gathering point. Despite it lacks the physiognomy and the formal importance of a square, it performs many of its public functions, so that often they are used as synonyms. In Portugal and in many other Mediterranean countries, a square is not a mere open space, nor a pedestrian path, nor necessarily a wide or regular space. On the contrary, it is a public open living place, the relation place par excellence, where people meet every day, so that the term itself is commonly figuratively used in current speaking to refer to society. This implies that, when we design an intervention on a square, we need to take first people into account and that the level of complexity and the number of inter-related design requirements can become extremely high. This is crucial for every public space especially if we consider the case of Lisbon, which must respond to the critical issue of accommodating a growing tourist population in a way that is sustainable, equitable, and inviting also for the locals. Because complex urban design problems can no longer be solved without prior or parallel research and the use/application of technology in the design/management of urban environments, a computational design research is applied, as a response to variations in performing criteria (Verebes, 2015). The presented study explores the contributions of multidimensional analyses to the design of a good public space able to make the city work better (Michel, 2007). The general research objectives of this work are part of a larger ongoing project whose final goal is to create an original multidimensional inductive method for the characterization and classification of public open spaces, able to gather descriptive and structural approaches to urban form in a single process and, finally, to conceive a urban design approach capable of generating quality urban design proposals. This paper has four sections. The first, introduces the existing techniques of digital analysis and public life studies, which are concerned with the relation between human behavior, social meaning and urban morphology. The second describes the proposed methodology. The third shows an application to urban design and the final section discusses the partial results obtained.

\section{Theoretical framework on digital analysis and public life studies}

The creation of meaningful typomorphological descriptions is essential in capturing the qualities trapped in urban structures and so classification has a fundamental role in the structuring of knowledge on cities. Even if we restrain ourselves just to modern authors of urban morphology, the problem of the classification of public open spaces, and among them 
the square, is recurring. The approaches tend to focus on geometrical or functional properties and run from the more intuitive to the more analytical (Sitte, Cloquet, Lavedan, Zucker, Choay, Krier, Guidoni among others). In the eighties, at the University College of London, Bill Hillier developed the Space Syntax theory (Hillier and Hanson, 1984), which is an analytical technique of spatial and configurational analysis of the urban environments, whose goal is to achieve a non-arbitrary and reproducible description and representation of space that allows the comparison between different spatial systems by considering space in terms of abstract properties of topological nature rather than in terms of built form or shape. The existing correlation between these properties and some urban phenomena has already been demonstrated by several authors (e.g. Hillier et al, 1993; Cutini, 2001). Thence, here, Space Syntax and in particular Axial analysis (Hillier and Hanson, 1984) and Visual Graph Analysis (VGA, Turner et al., 2001) are used to approach public space by focusing on the determination, and then representations, of syntactic quantifiable measures that expose the rules of the social construction and of the perceptive-cognitive apprehension of spaces. Most of these analyses are only possible through computational means.

The origin of public life studies, or rather the study of urban phenomena, according to the democratic ideal of public life through the use of public space, even if only from an intuitive and aesthetic viewpoint, is believed to have its precursor in Camillo Sitte. Even so, it had a considerable development only in the 1960's when a few urban designers and planners started to rethink the roles of the public space from a people-centric perspective and to stress the importance of the citizen's apprehension of the city. These tendencies become increasingly systematic with the contribution of, for instance, Lynch (1960), Jacobs (1961), Cullen (1961), Whyte (2001) and Jan Gehl (2011). The keywords of Gehl's research are: action research, area studies, behavioral mapping, pedestrian activity, photo documentation, social responsibility, stationary activity, sustainability, time-lapse photography, tracking, urban policy etc. The techniques developed by him are believed to be highly valuable when it comes to add details, test and validate the results of digital analyses, thus, here it is proposed to use them in combination with additional advanced computational tools in order to help the decision-making of the parametric design process for Largo da Graça.

\section{A multi-scale and multidimensional methodology for the study of public spaces}

This Design Research study seeks to understand the spatial structure and the character of Largo da Graça both locally and as part of the city of Lisbon within a multi-scale and multidimensional approach. Methodologically (Figure 1), this academic research collects concepts and tools from the urban morphology, algorithmic design, environmental and public life studies (Paio et al, 2016). The design process encompasses five stages:

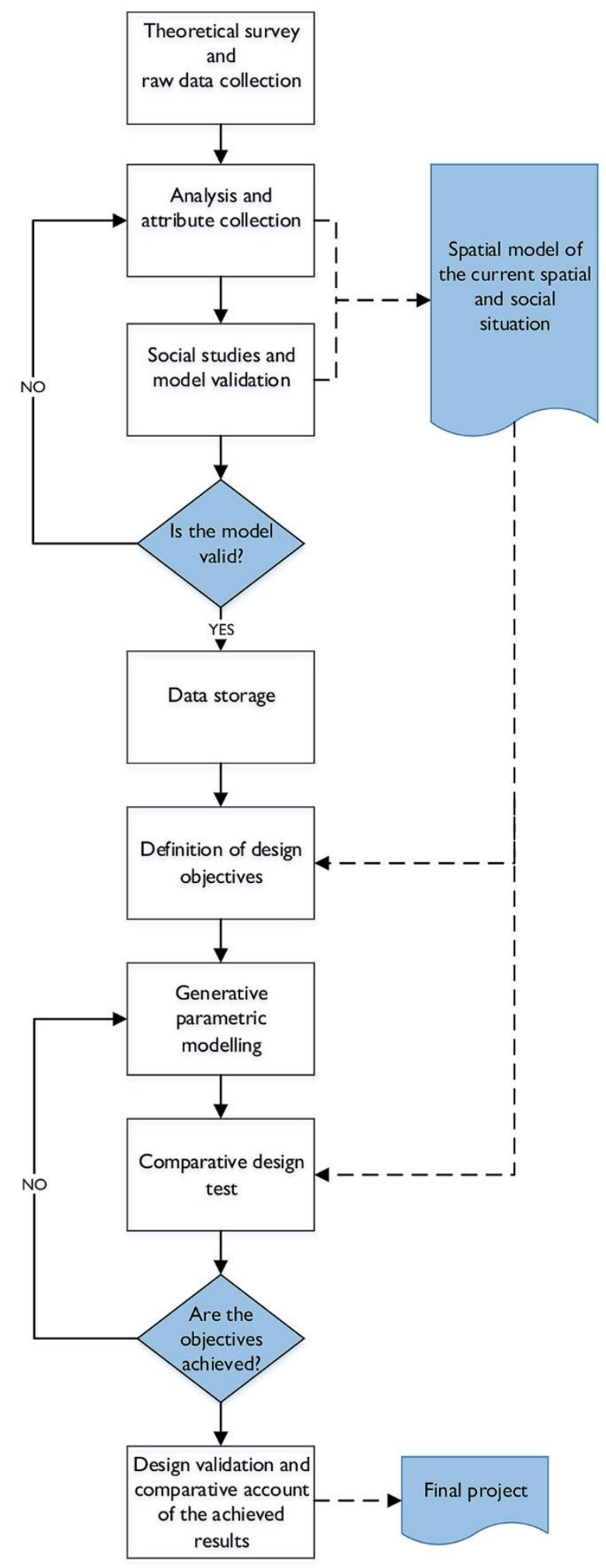

Figure 1: flowchart of the proposed methodology.

\section{Stage 1: definition of the significant attributes}

In the first stage, the designer needs to survey on theories, methods and spatial analysis tools. After firming the concepts and criteria a significant and 
heterogeneous set of formal and spatial (metric, geometric and topological-syntactic), environmental and perceptual-cognitive attributes are then defined. In this implementation, the analysis was restricted to a set of ten attributes divided in four main themes: 1. Accessibility and connectivity, through the Visual Graph Analysis. 2. Urban System, global characteristics of the urban structure where the square is embedded, through Space Syntax axial analysis. 3. Uses and functions. 4. Environmental characteristics.

\section{Stage 2: model construction and data extraction}

In the second stage, the designer mines the data through the computational processing of the previously created $2 \mathrm{D}$ and $3 \mathrm{D}$ digital models of the city and of the square in a semi-automatic workflow. For the production of those models and the extraction of data, different software is used depending on the type of data. Besides standard CAD tools, it was used Depthmap (UCL), QGis, and Rhino together with Grasshopper and some of its plugins (namely Ladybug and Honeybee by Mostapha Sadeghipour Roudasri, Kangaroo by Daniel Piker, and SpaceSyntax by Pirouz Nourian). Thanks to the programming interface of Grasshopper it is possible to develop some algorithms for the extraction of the information from the 2D and 3D models of the square and then store them for subsequent data analysis.

\section{Stage 3: model validation by direct observations}

In the third stage, the designer studies the square in its actual configuration by means of the observation of its public life. Thus, people's movements are traced on a plan and their number is counted while the stationary activities are mapped in parallel. This allows the designer to test the reliability of the model, so that it can guide the decision making of the design process and produce accurate forecasts at a later stage. This is possible only thanks to the fact that the existent literature shows the relationships between human behavior and the selected attributes.

\section{Stage 4: development of an iterative design process}

In the fourth stage, the designer finally approaches the project using a comprehensive parametric/algorithmic logic, which enables the use of the previously analyzed variables as design-driving parameters. Furthermore, this logic structures the iterative and interactive process between analysis and design, being a step-by-step process for performing the design activity. At this stage, the visual programming interface (VPI) of Rhino/Grasshopper appears extremely useful. In fact, it is crucial to find an efficient design solution when it comes to the environmental analysis of the comfort features of the square, and also to solve, by subsequent parametric modelling, the critical points highlighted by the configurational analysis and then confirmed by the tests.

\section{Stage 5: final design and validation test}

In the fifth stage, the designer tests the final design outcome and numerically evaluates the effectiveness of the proposed design in improving the chosen quality parameters of the public space. Furthermore, predictions on the expected public life can be done, based on proven theory and the results of a comparative analysis between the current situation and the final design

\section{Analysis-based public open space design}

Square means size, centrality, enclosure, architectural quality and unitary image. This is strictly dependent from properties such as visibility, connectedness and accessibility, which relate to the number of people using the streets. Translated into Space Syntax words, the quality of a square depends on a high value of the clustering coefficient, connectivity (or neighborhood size) and integration, which can be studied separately or combined in the Interaction index (Cutini, 2003) and finally compared to other environmental factors (Figure 2).

\section{Analysis at a global scale}

First of all, a series of attributes is retrieved at a bigger scale, such as the distribution of the configurational indexes on the axial lines of Lisbon, among which the Integration index, that describes the level of global (radius n) and local (radius 3) centrality (or to movement in space syntax terminology) of Largo da Graça, and Choice (through movement), which maps the major flows that run through the city, giving an account of the accessibility of the square and of the number of people who may cross it. From the analysis the area of Largo da Graça turns out to be a microcentrality with a great potential as a public space.

\section{Analysis at a local scale}

At this scale, an environmental analysis is used, as a strategic tool, to identify all the external and internal elements, which can affect the square's performance. These evaluations are later translated into the decisionmaking process.

Since the spatial properties of the square appear vital to the success of the design proposal, another configurational analysis is done at a local level and at a smaller scale. This is the visual graph analysis (VGA), which combines Benedikt's (1979) isovist concept with the typical graph based analysis of Space Syntax. VGA allows visualizing the variation in the values of the syntactic indexes inside the two-dimensional space of the square. It identifies the areas easier to control and hence, where people prefer to stay to look at other people and the visual barriers. 


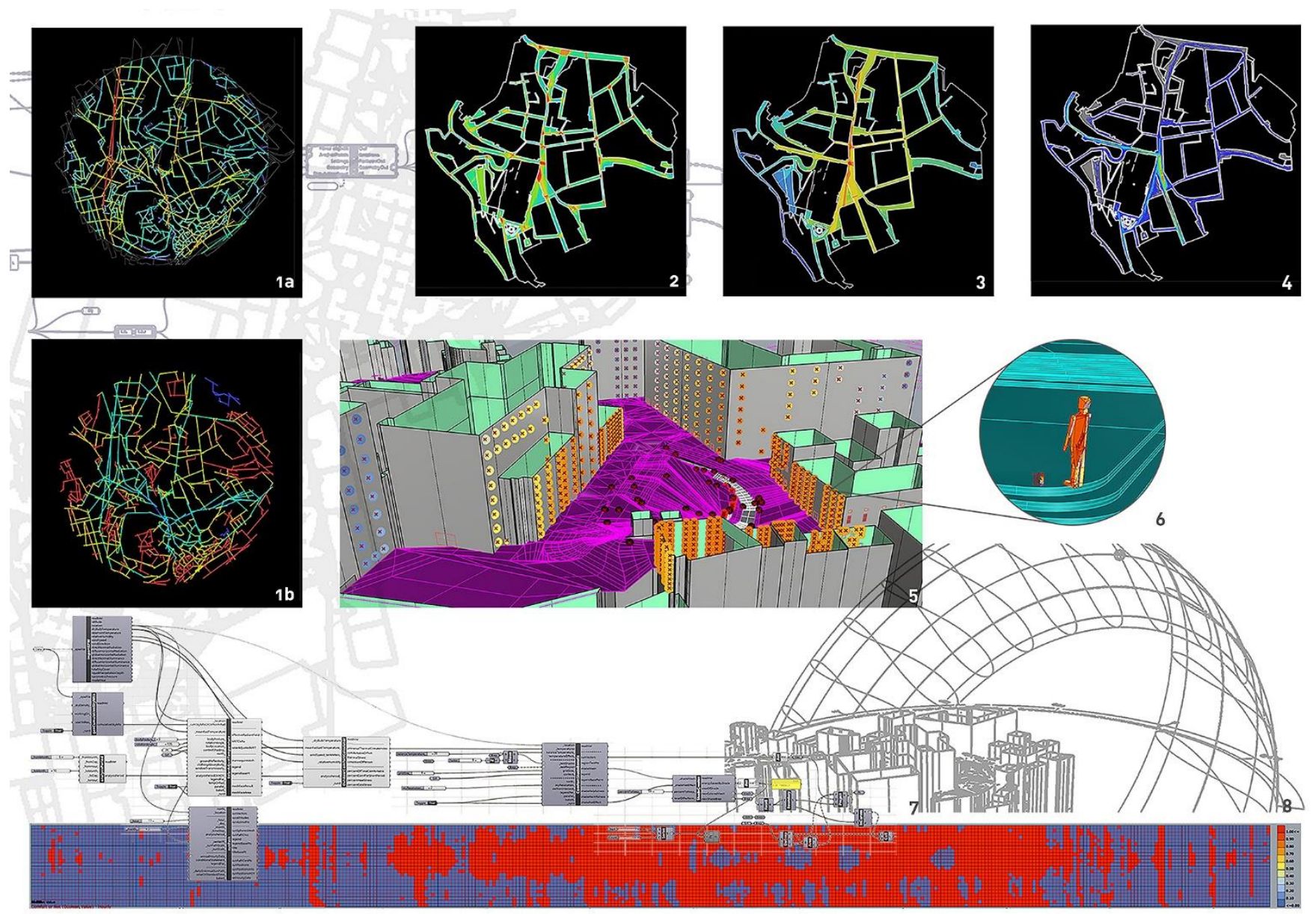

Figure 2: Square multidimensional analysis. 1a|b. axial and segment analysis; 2. VGA control; 3. VGA integration; 4. Depthmap's agent analysis; 5 . Visibility 3D; 6 . outdoor comfort calculation; 7 . environmental analysis; 8 . shade optimization.

Besides visibility conditions, the microclimate, that is, the local climate of a specific site, has a heavy impact on whether people stay because for stationary activities a higher level of environmental quality is required. Therefore, using Lisbon's weather data, it was made a thermal analysis with the objective of assuring to the square a sufficient level of outdoor comfort during the entire year. Defined the conditions of no thermal stress when the perceived outdoor temperature is between 9 and 26 degree Celsius, Ladybug enabled to determine the total percentage of comfortable hours during the entire year, $47 \%$ in the city of Lisbon, which is not an excellent result. It was crucial for the purpose of the project, to derive the chart representing the specific comfortable (red) or uncomfortable (blue) thermal conditions of Largo da Graça for each hour of the year. In fact the chart highlighted the extreme condition of discomfort, due to the excessive heat, that occurs from May to October in the central hours of the day, threatening the full enjoyment of the public space during the warmer season.

\section{Direct observation and validation of the model}

A sufficient number of in situ observations were done, in order to validate the model and the obtained results. People's movements were traced on a plan of the square and the position of stationary activities was mapped. At a later time the two representations were overlapped and integrated with numeric data and photographic documentation. The resulting picture appeared in good accordance with the results of the configurational analysis (Figure 3). At this point the model was considered definitively validated and then it was used for testing the various design proposals.

\section{Iterative parametric design}

A geometric regular grid is created in order to structure, hierarchize and define the square's spaces and built components, their functions and spatial dispositions. The concept derives from the Portuguese Azulejos, which are a distinctive architectural trait of Lisbon and in particular of its oldest neighborhoods. In this way the intention is to link the project to something that already belongs to the spirit of the place and to its history, thus combing a practical necessity with an emotional instinct. Moreover the patterns used in the azulejos have many interesting geometric properties, among which a rigorous design with a multi-level hierarchical nature, which enables the same pattern to recur at different scales and thence to adapt to many scales of interventions always following the very same algorithmic logic. 


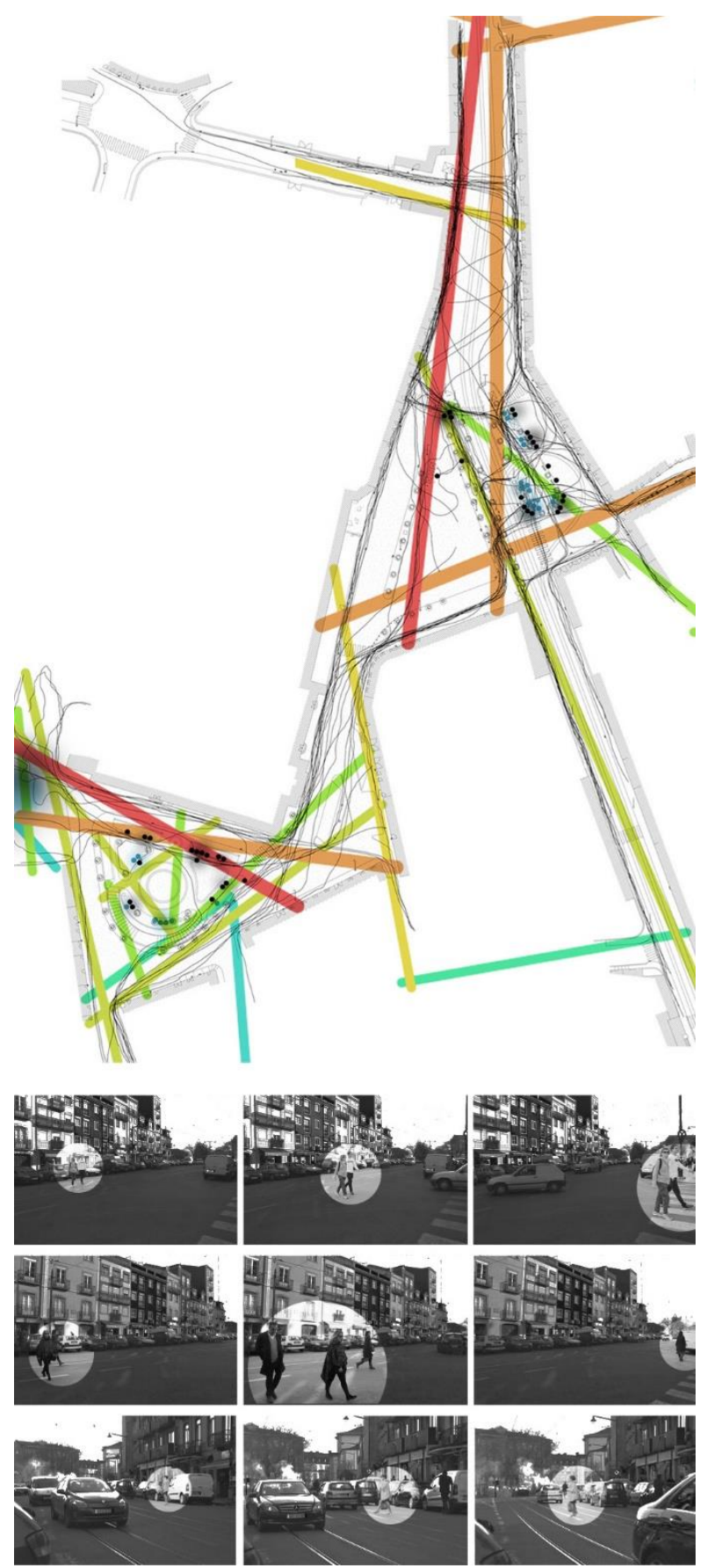

Figure 3: Tracking, mapping and time-lapse photography techniques of studying outdoor activity, combined with axial lines, showing the distribution of local axial integration.

In order to be able to scale and rotate the adopted pattern (Figure 4) as required, it was made a parametric definition of its construction by the use of Grasshopper, which allowed for the necessary flexibility, especially in the first phases of the design process. Starting from this base definition some elements can immediately be derived: a grid of points, three main linear directions and finally an infinite set of possible areas, which are the start point for the subsequent design.

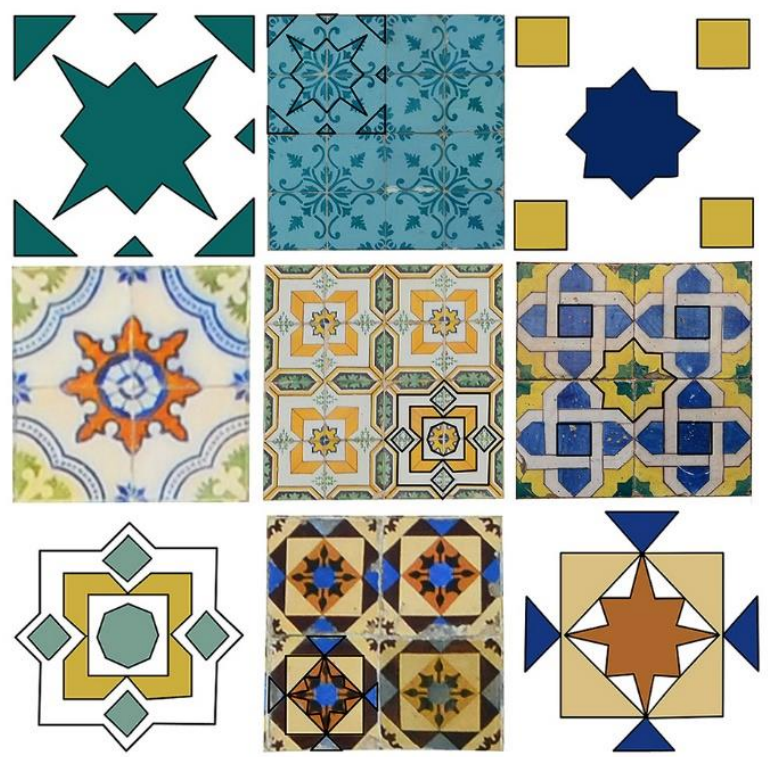

Figure 4: Portuguese azulejos: A kind of glazed colored tile traditionally used in Spanish and Portuguese buildings as a wainscot or facing.

\section{New visibility fields}

The first step was to break down the visual barriers identified by means of the VGA analyses in which the stairs were marked as an impediment. Therefore, the vertical connections between the different levels of the square were re-designed. In the case of the North part of the square the height-difference was used to build a system of consecutive small squares, whose drawing is derived from the grid, following the W. Whyte (2001) four steps maximum principle, with the aim of inviting people inside an elevated square. "The area where the street and the plaza or open space meet is a key to success or failure. Ideally, the transition should be such that it's hard to tell where one ends and the other begins" (Whyte, 2001, p.57). Here, the people in the lower smaller squares provide the show to the people in the upper level, who are as in the tiers of an amphitheater. As a result the orography of the site is redesigned taking into account the constraints represented by the doors along the square's borders and the historic heritage. This intervention allows an extension of the view lines over the entire area and the elimination of many barriers resulting in a better local accessibility.

\section{Physical and functional connections}

In order to connect physically and functionally the designed square to the surrounding buildings, the design for the new paving followed a simple principle: integrate places for moving and places to stay in a unitary, but ordered system. A special attention was put to create continuous flooring that, following the lines of the basic grid was able to connect all the doors in order to create a pedestrian route-space functional and wide. The remaining areas were divided into two qualitatively different parts: green spaces generally located along the square's perimeter and paved zones, which are the 
actual core of plaza and represent the places to stay, to seat and to contemplate. In fact they are designed to invite the stationary activities, providing a large and feasible number of places to sit, good visibility conditions and close proximity to the walking paths, besides a better comfort condition given by the construction of a proper shading system, whose design follows the same generative rules of the entire intervention (Figure 5). All the described areas are coherently highlighted by the use of different materials, namely the black basalt for the strolling paths and the white limestone for the places to stay, together with the ceramic azulejos themselves.

\section{Outdoor comfort regulation}

Comfort in architecture relates to several aspects of how a space is designed and there are many psychological/ perceptual factors involved, as in the case of the perception of security, which is conveyed not only by the space configurational properties, but also by materials, colors, shapes and visual language. Among these aspects, thermal comfort, which is the satisfaction of the occupants with the surrounding thermal conditions, is essential to consider when designing a place for people. Therefore, being Lisbon in the hottest zone of Europe, the thermal factors are of primary importance.

To solve the current heat-related critical issues, it was opted for a removable and adjustable tensioned textile curtain, tied to a steel cable net structure. This curtain or screen would leave a strong architectural sign all over the square, thus covering and connecting the different spaces with a unifying element. Furthermore, would give a sensible response to a technical necessity, and echoing the Mediterranean and Arabic tradition of lightweight textile shading devices. Furthermore, the decision was based on reasons of economic convenience, ease of assembly and disassembly, flexibility and ability to cover large areas without resorting to heavy and invasive structures. To sum up the design of the coverage responds to multiple necessities: to give a unitary image to the square by clearly delimiting its space, to produce a better summer thermal condition that would allow the people to stay there and finally to permit to the structuring pattern to work in the 3D volume defined between the ground and the cover. To test the design it was used a Ladybug component called Comfort Shade Benefit Evaluator, which was created on the base of the Shaderade method developed by Sargent et al. (2011), but substitutes Shaderade's energy simulation with an evaluation of heating and temperature degree-days about a balance temperature which was settled at 20 degree Celsius. Here the points of the analysis grid of the square were projected onto the proposed modular, triangular shaped, shading test surfaces along the direction of the average summer solar ray. The iterative process, finally selected an optimized the number of shading test surfaces which compose the final design. Its final shape is then the outcome of a form finding process that tried to maximize the comfort revenue while minimizing the construction costs, which resulted in a $38 \%$ of covered area with a saving of 5,57 degree- days against the 8,92 corresponding to the $100 \%$ coverage.

\section{To build with Greenery, Water and Light}

Despite the recognized importance of the thermal factors, again, comfort it is not just about temperature control, but it also depends on how an architectural built form engages occupants through all of their senses. More specifically, it is the result of the harmonization between every environmental factor such as lighting, materiality, sound, and so on. Therefore, some further adjustments were made to the design in order to improve the interaction between the existing elements and the people. Thus, the fences that divided the green and the water from the people disappear. The green was re-designed in a way that it helps the coverage in its function, frame the wind, mark the grid points and lead the visitors to the center of Largo da Graça. The fountain was moved from the center of the square to a more convenient location of the grid where people can sit and enjoy its sound and its conveyed feeling of privacy. The lighting system was re-thought according to the new functional program and to the indications of the configurational analysis made on the design model base, resulting in a non-regular planimetric and height distribution of the street lamps.

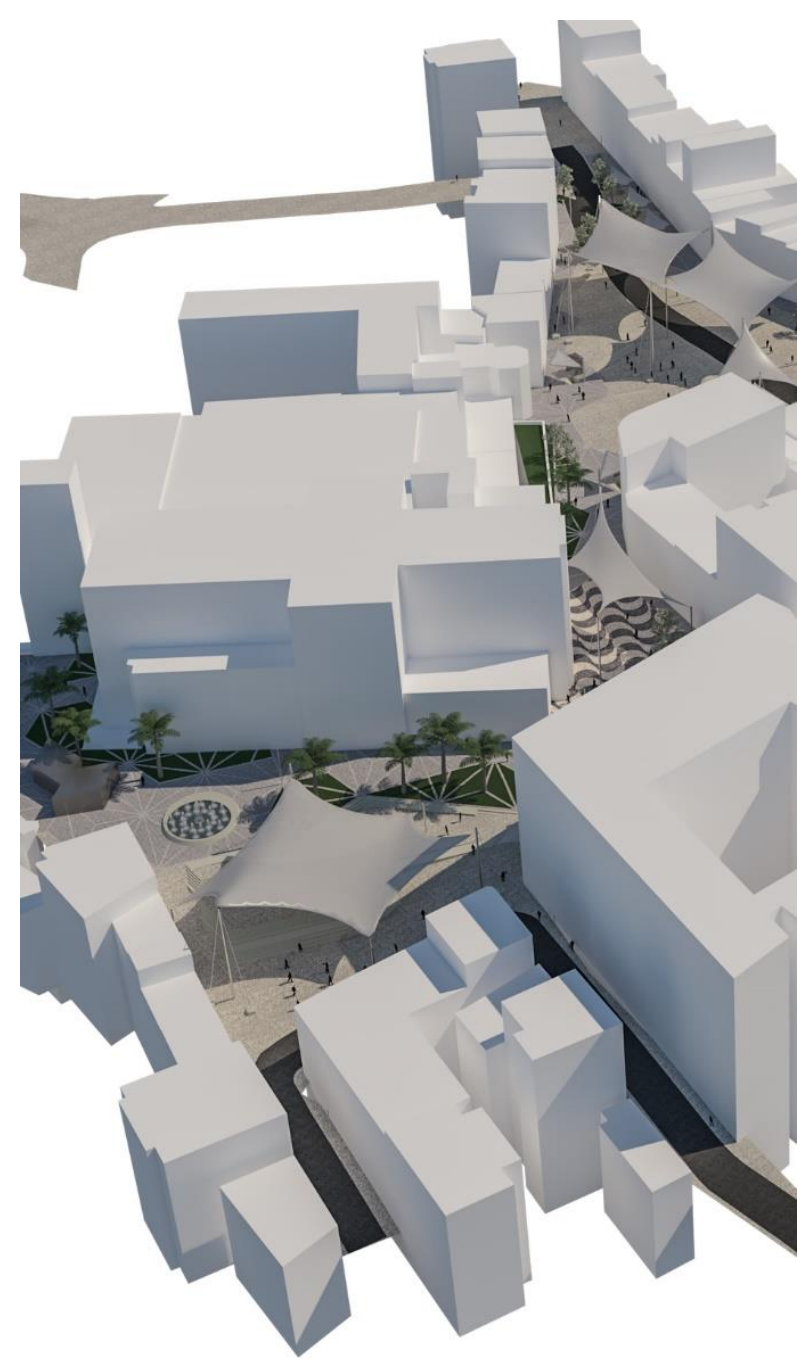

Figure 5: bird's-eye view of the design proposal. 


\section{Final test and design validation}

All the interventions are organized as to invite occupation and promote activities that enhance social interaction. The final proposed outcome is the last of a series of targeted sectorial adjustments, which should allow the realization of the programmatic goals, themselves re-adjusted after the analyses. The designed space is the hardware that should support the functioning of the software that is precisely the general program decided for the plaza. In order to responsively adapt to its possible changes, to allow the public participation and to get external specialized contributions at any phase of the design process, the overall procedure is based on a parametric generative logic able to respond to changing needs, guide the decision making and ultimately to give structure to a spaces which before lacked coherence. The final testing assesses the quality level achieved by the proposed design and furthermore it enables a comparative ranking of the after and before configurations, again by means of digital analyses. A VGA test was made taking into account the final proposed spatial layout and the results are visible in Figure 6. The level of local accessibility and centrality raised, as well as the values of Connectivity and of the Clustering coefficient which, combined, resulted in an increment of the $28 \%$ of the Interaction index value. In terms of visual Control there are improvements too: the control area expands towards the central spaces of the square instead of occupying just the corners. This is interpreted as a centralization of stationary activities which is believed to be the key for the achievement of an active occupation of the entire square's area. A final test is done using a Space Syntax agent based analysis (with Depthmap) which is used to generate aggregate models of people's movement in space. The result of the analysis proves that thanks to the final design proposal we would be able to lead more agents inside the square and to its central areas (Figures 2 and 6).
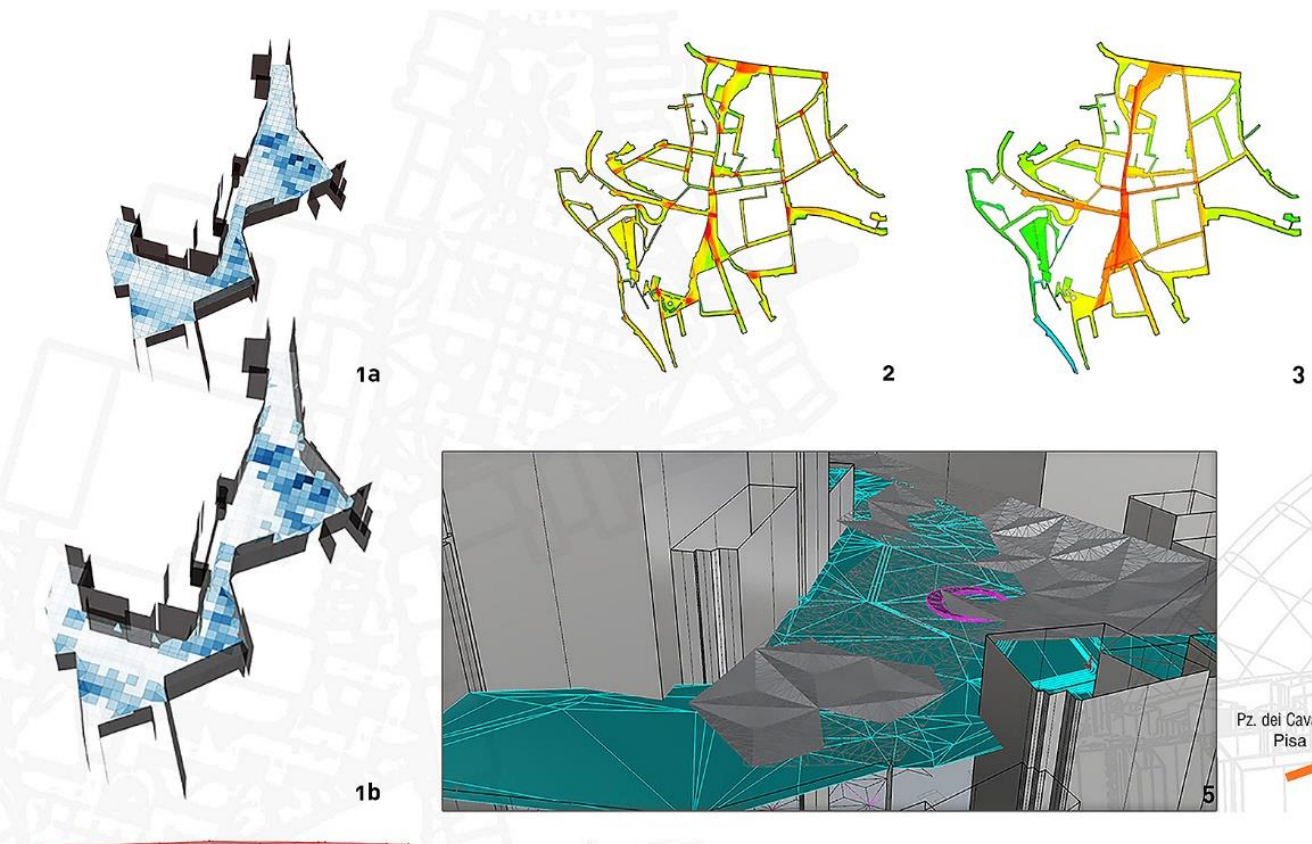

3

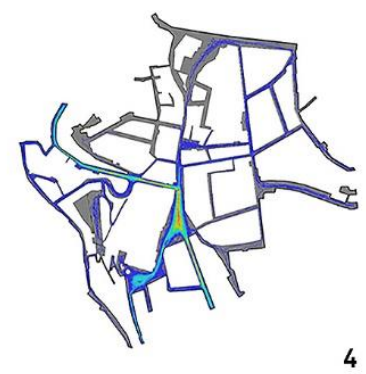

4

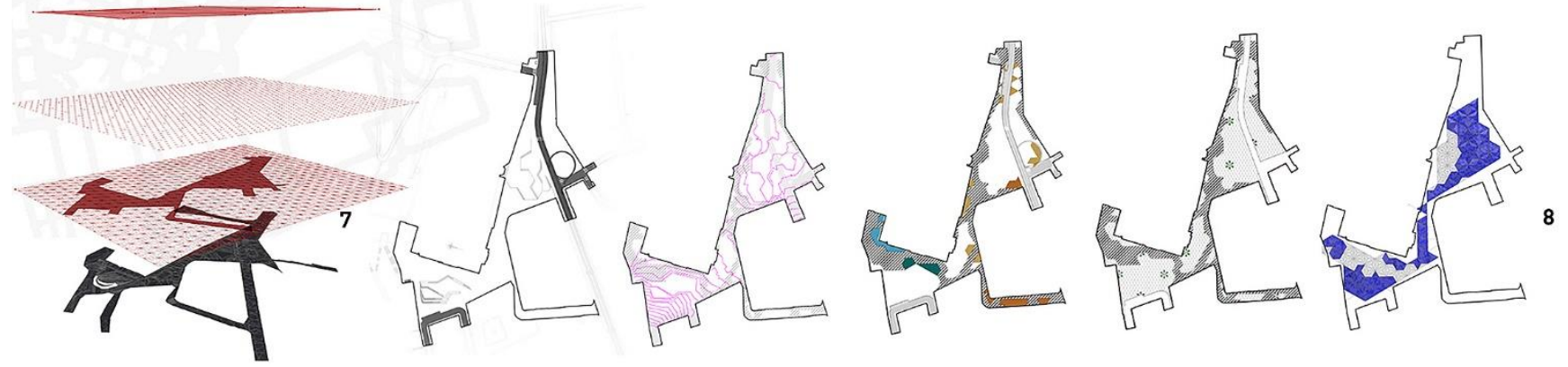

Figure 6: Square Design and Multidimensional analysis test. 1a|b. environmental analysis; 2.VGA control; 3. VGA integration; 4. Depthmap's agent analysis; 5 . Comfort Shade Benefit evaluator 3D result; 6.outdoor comfort calculation; 7.grid and pattern superimposition; 8. layering of the developed design : in order from left to right viability, orography, green areas, paving, the covering. 

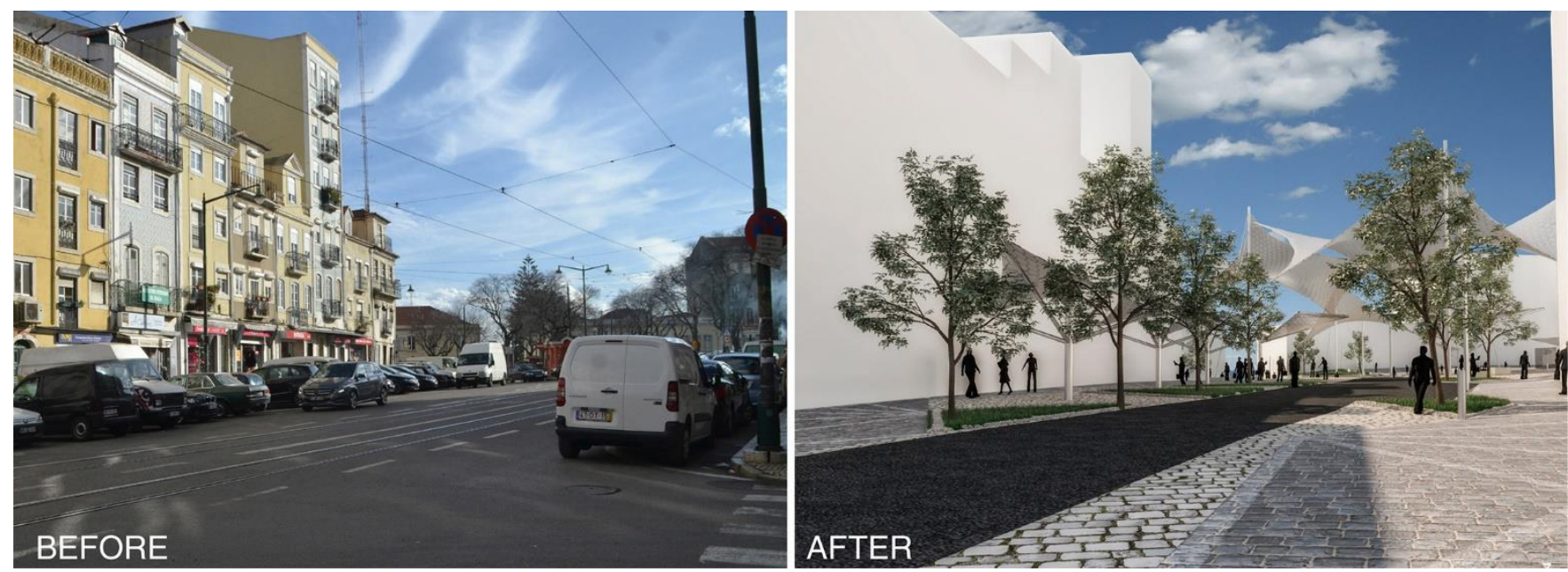

Figure 7: example of the after and before situations.

\section{Conclusions}

The support that the presented comprehensive set of analyses gave during the development of the design has been fundamental to guide the decision-making process that led to the final output (Figures 5 and 7). However, the most valuable property of the adopted methodology is that it can be part of a potentially openended and adaptable strategy, which can be applied to other urban designs. The studies done in the first part of the process have helped in the definition of the design objectives and provided a valid tool for successive comparison and verification. The adopted generative logic seems to respond well to the established requirements of generality and adaptability of the method, and to deal with more complexity. In fact, it enables at any stage of the design process, the introduction of a wider spectrum of inputs, thus the implementation with further analyses (at disparate spatial scales and problem dimensions) for the testing of the project. In the future, these studies can be used as input in the decision-making process, as part of overall planning, or in designing individual projects such as streets, squares or parks. This can improve our ability, as designers, to respond to the growing complexity of contemporary cities.

\section{References}

Benedikt M. (1979). To take hold of space: isovists and isovist fields. Environment and Planning B:Planning and Design, 6.

Cullen, G. (1961). The concise townscape. Oxford: The Architectural Press.

Cutini V. (2001). Configuration and Centrality Some evidence from two Italian case studies. Proceedings of the 3rd International Space Syntax Symposium.

Cutini V. (2003). Lines and squares: towards a configurational approach to the morphology of open spaces. Proceedings of the 10th International Space Syntax Symposium.

Gehl, J. (2011). Life Between Buildings. Using Public Space. London: Island Press.

Hillier, B. \& Hanson, J. (1984). The Social Logic of Space. Cambridge: Cambridge University Press.
Hillier, B., Penn, A., Hanson, J., Grajewski, T., Wu, J. (1993), Natural Movement:or, Configuration and Attraction in Urban Pedestian Movement. Environment and Planning B, 20.

Hillier, B. (1996). Space is the machine: a configurational theory of architecture. Cambridge: Cambridge University Press.

Jacobs, J. (1961). The Death and Life of Great American Cities. New York: Random House.

Lopes,J., Paio, A., Beirão, J.N., Pinho, E.M., Nunes, L. (2015) Multidimensional Analysis of Public Open Spaces - Urban Morphology, Parametric Modelling and Data Mining. Proceedings of the 33rd eCAADe Conference, Vol 1.

Lynch, K. (1960). The image of the city, Cambridge Massachussetts: MIT Press.

Michel, R. (2007). Design Research Now. Essays and Selected Projects. Basel: Birkhäuser.

Paio, A., Cutini, V., Pezzica, C, Lopes, J. Bevilacqua,M.(2016) Urban Squares Morphologies: Contributions of a Multidimensional Analysis. Nexus 2016, Architecture and Mathematics Abstracts. San Sebastian: Kim William Books.

Seargent, J.A.,Niemasz, J., Reinhart, C.F. (2011). Shaderade: combining rhinoceros and energy plus for the design of static exterior shading devices. Proceedings of 12th Conference of International Building Performance Simulation Association.

Sitte, C. (1953 [1889]). L'arte di costruire le città. Milano: Officine Grafiche dell'Editore Antonio Vallardi.

Turner, A., Doxa, M., O'Sullivan, D. \& Penn, A. (2001). From isovists to visibility graphs: a methodology for the analysis of architectural space. Environment and Planning B: Planning and Design, 28.

Verebes, T. (guest-editor). (2015). Mass-customised Cities. AD Architectural Design, 06, Vol. 85.

Whyte W.H. (2001 [1980]). The social life of Small Urban Spaces, Ann Arbor: Edwards brothers 